\title{
THE ROLE OF MACROPRUDENTIAL POLICY TO MANAGE EXCHANGE RATE VOLATILITY, EXCESS BANKING LIQUIDITY AND CREDITS
}

\author{
Muhammad Edhie Purnawan \\ M. Abd. Nasir
}

\begin{abstract}
This paper analyzes the macroprudential policy by the central bank to maintain the financial system stability. Using panel data of the government banks, foreign, private, joint venture, and regional development banks during 2004- 2012, we employ Vector Autoregressive Exogenous (VARX) and event analysis method and find that the level of exchange rate volatility decrease after the implementation of the one month holding period, six-month holding period and net open position policies. However, for the nominal exchange rate, these policies are not effective. In aggregate the reserve requirement plus loan to deposit ratio policy is effective to raise the bank credit allocation. Furthermore, the impact of the primary reserve policy is very limited to lower the liquidity of the economy; while at the same time the flow of foreign capital comes into very heavy
\end{abstract}

Keywords: macroprudential policy, VARX, event analysis, holding period, net open position, reserve requirement, banking.

JEL Classification: E51, E58, E60, E69

1 Muhammad Edhie Purnawan (corresponding author: edhiepurnawan@ugm.ac.id) is Vice Dean at the Faculty of Economics and Business, Universitas Gadjah Mada ; M. Abd. Nasir (email: abdulnasir1705@gmail.com) is Lecturer at the Department of Economics and Development Studies, Faculty of Economics, University of Jember. 


\section{PENDAHULUAN}

Istilah "makroprudensial" pertama kali digunakan pada akhir tahun 1970 dalam dokumen yang tidak dipublikasikan oleh Cooke Committee (pendiri Basel Committee on Banking Supervision) dan Bank of England (Clemment, 2010: 2). Terdapat beberapa definisi mengenai kebijakan makroprudensial. Menurut versi Working Group G-20 (2010: 4), kebijakan makroprudensial adalah kebijakan yang ditujukan untuk meningkatkan ketahanan sistem keuangan dan untuk memitigasi risiko sistemik yang timbul akibat keterkaitan antar institusi dan kecenderungan institusi keuangan untuk mengikuti siklus ekonomi (procyclical) sehingga memperbesar risiko sistemik.

Krisis yang terjadi di Amerika Serikat pada bulan September 2008 yang kemudian menular ke berbagai negara di dunia menunjukkan bahwa ketidakstabilan di sektor keuangan berdampak serius pada sektor riil (Agung, 2010: 2). Krisis keuangan yang didorong oleh penggelembungan kreditberubah menjadi krisis global dan telah menyebabkan aktivitas perekonomian turun drastis.

Claessens et al., (2012: 9) dan Hahm et al.,(2011: 15) berargumen bahwa ada 3 pelajaran penting dari krisis finansial. Pertama adalah dampak dari perkembangan di sektor keuangan ke sektor riil ternyata lebih besar dibandingkan perkiraan semula. Kedua adalah biaya dari penyelamatan krisis sangat besar. Ketiga adalah stabilitas harga dan output ternyata tidak menjamin kestabilan finansial. Oleh karena itu, disusun suatu kerangka kebijakan guna menanggulangi ketidakstabilan sistem keuangan yaitu kebijakan makroprudensial.

Berdasarkan argumen Angelini et al., (2012: 20) dan Tovar et al.,(2012: 27) instrumen makroprudensial digunakan untuk memitigasi tiga kategori dalam risiko sistemik, yaitu risikorisiko yang ditimbulkan akibat pertumbuhan kredit yang terlalu kuat, risiko likuiditas, dan risiko akibat arus modal masuk yang deras. Beberapa instrumen kebijakan makroprudensial yang selama ini telah dilakukan oleh Bank Indonesia antara lain month holding period (MHP), Posisi Devisa Neto (PDN), Giro Wajib Minimum (GWM) primer, dan GWM+LDR (Loan to Deposit Ratio).

Month Holding Period (MHP) merupakan kebijakan yang mewajibkan pembeli Sertifikat Bank Indonesia (SBI) baik di pasar primer maupun di pasar sekunder menahan kepemilikan SBInya selama periode waktu yang telah ditentukan yaitu 1 bulan (OMHP) dan 6 bulan (SMHP) sejak tanggal pembelian, sebelum dapat mentransaksikannya kepada pihak lain. Kebijakan month holding period (MHP) bertujuan untuk mengurangi volatilitas aliran dana di SBI dan meningkatkan efektivitas pengelolaan moneter. Kebijakan ini diharapkan dapat meminimalkan dampak negatif aliran modal asing yang bersifat spekulatif atau bersifat jangka pendek terhadap stabilitas moneter dan sistem keuangan serta dapat mendorong transaksi lainnya di pasar uang. ${ }^{2}$

2 Penjelasan tentang month holding period berdasarkan Peraturan Bank Indonesia. Nomor: 12/ 11 /PBI/2010 Tentang Operasi Moneter 
Posisi Devisa Neto (PDN) adalah angka yang merupakan penjumlahan dari nilai absolut untuk jumlah dari selisih bersih aktiva dan pasiva dalam neraca untuk setiap valuta asing ditambah dengan selisih bersih tagihan dan kewajiban baik yang merupakan komitmen maupun kontinjensi dalam rekening administratif untuk setiap valuta asing, yang semuanya dinyatakan dalam rupiah. ${ }^{3}$

Giro Wajib Minimum (GWM) adalah simpanan minimum yang wajib dipelihara oleh bank dalam bentuk saldo rekening giro pada Bank Indonesia yang besarnya ditetapkan oleh Bank Indonesia sebesar persentase tertentu dari Dana Pihak Ketiga (DPK). ${ }^{4}$ GWM + LDR (Loan to Deposit Ratio) merupakan simpanan minimum yang wajib dipelihara oleh bank dalam bentuk saldo rekening giro pada Bank Indonesia sebesar persentase dari DPK yang dihitung berdasarkan selisih antara LDR yang dimiliki oleh bank dengan LDR target (Peraturan Bank Indonesia, 2010). ${ }^{5}$

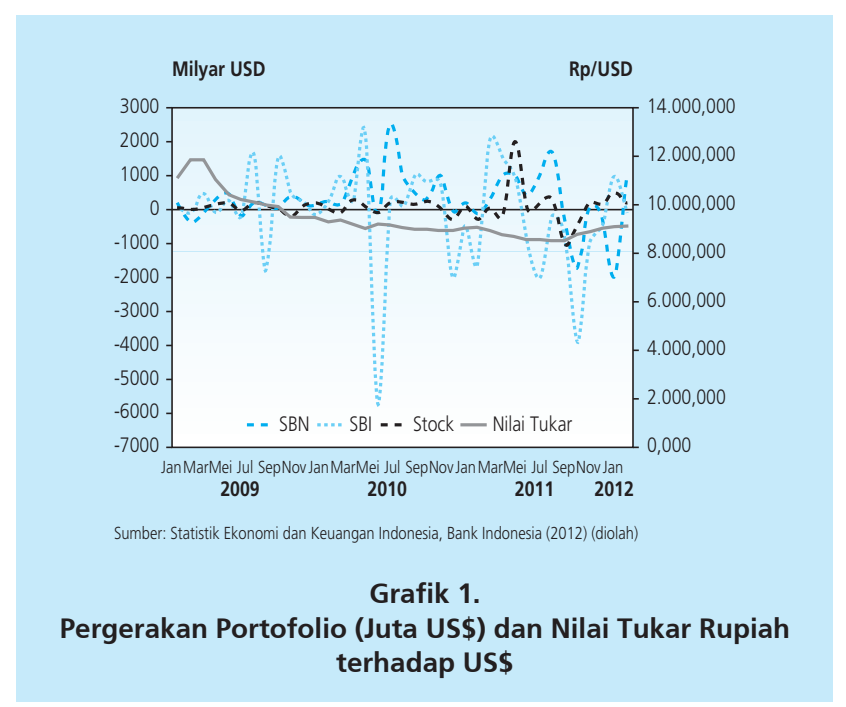

Grafik 1 menunjukkan bahwa setelah diberlakukannya komponen kebijakan makroprudensial, nilai tukar rupiah cenderung mengalami penurunan dan relatif stabil di level yang rendah. Namun demikian, terlihat nilai tukar cenderung stabil setelah diberlakukan kebijakan, tetapi kembali mengalami tren kenaikan setelah diberlakukan kebijakan.

3 Berdasarkan Peraturan Bank Indonesia Nomor: 5/13/PBI/2003 Tentang Posisi Devisa Neto Bank Umum kemudian disempurnakan menjadi Peraturan Bank Indonesia No.12/10 /PBI/2010 Tentang Perubahan Ketiga atas Peraturan Bank Indonesia. Nomor 5/13/ $\mathrm{PBI} / 2003$.

4 Berdasarkan Peraturan Bank Indonesia Nomor: 12/19/PBI/2010 Tentang Giro Wajib Minimum Bank Umum Pada Bank Indonesia Dalam Rupiah Dan Valuta Asing

5 Penjelasan tentang GWM + LDR ini berdasarkan Peraturan Bank Indonesia Nomor 15/7/PBI/2013 Tentang Perubahan Kedua Atas Peraturan Bank Indonesia Nomor 12/19/PBI/2010 Tentang Giro Wajib Minimum Bank Umum Pada Bank Indonesia Dalam Rupiah Dan Valuta Asing 
Berdasarkan penelitian Hahm et al., (2009) tentang efektifitas penggunaan instrumen kebijakan makroprudensial di Korea Selatan menunjukkan bahwa kebijakan Loan to Value (LTV), LDR, dan GWM sebagai instrumen makroprudensial sangat efektif untuk mengurangi siklus kredit. Berbeda dengan hasil penelitian yang dilakukan oleh Bustamante et al., (2012) yang mana efektifitas penggunaan instrumen makroprudensial di Kolombia menunjukkan bahwa kebijakan LTV kurang efektif diterapkan.

Peneliti lain yaitu Tovar et al., (2012) dalam penelitiannya di Brazil, Kolombia, dan Peru menunjukkan bahwa penggunaan instrumen makroprudensial berupa GWM efektif diterapkan di Brazil dan Peru, sedangkan di Kolumbia tidak. Kemudian Lim et al., (2011) mengevaluasi efektifitas penggunaan instrumen makroprudensial dalam mengurangi risiko sistemik di 49 negara. Mereka berargumen bahwa sebagian besar instrumen (LTV dan GWM) efektif dalam mengurangi prosiklikalitas, tetapi efektivitasnya sangat tergantung pada guncangan di sektor finansial.

Berdasarkan uraian tersebut, maka pada penelitian ini akan dibatasi oleh dua pertanyaan penelitian; pertama, bagaimana pergerakan sasaran instrumen kebijakan makroprudensial sebelum dan setelah kebijakan tersebut diimplementasikan?; dan kedua, bagaimana efektifitas instrumen kebijakan makroprudensial (month holding period, posisi devisa neto, giro wajib minimum, dan giro wajib minimum + loan to deposit ratio) yang telah diterapkan di Indonesia?

Bagian selanjutnya dari paper menguraikan landasan teori dan kajian empiris terkait. Bagian ketiga menguraikan data dan model empiris yang digunakan. Bagian keempat menyajikan hasil dan analisis, sementara kesimpulan dan saran disajikan pada bagian kelima dan menjadi bagian penutup.

\section{TEORI}

Kebijakan makroprudensial adalah instrumen regulasi prudensial yang ditujukan untuk mendorong stabilitas sistem keuangan secara keseluruhan, bukan kesehatan lembaga keuangan secara individu (International Monetary Fund, 2013: 12; Schloenmaker dan Peter, 2011: 23). Tujuan kebijakan moneter adalah menstabilkan harga barang dan jasa dalam perekonomian. Sementara itu, tujuan dari kebijakan makroprudensial adalah untuk menjamin daya tahan sistem keuangan secara keseluruhan dalam rangka menjaga suplai jasa intermediasi keuangan kepada perekonomian secara keseluruhan (Quint dan Pau, 2011: 11 dan Milne, 2009: 19).

Terdapat dua dimensi penting dari kebijakan makroprudensial (Claessens et al., 2012: 98; Tovar et al., 2012: 29; dan Lima et al., 2012: 19). Pertama, dimensi cross section, yang menggeser fokus dari regulasi prudensial yang diterapkan pada individual lembaga keuangan menuju pada regulasi sistem secara keseluruhan. Dimensi kedua adalah dimensi time-series, 
yaitu kebijakan makroprudensial ditujukan untuk menekan risiko terjadinya prosiklikalitas yang berlebihan dalam sistem keuangan.

Tujuan dari kebijakan makroprudensial yang bersifat countercyclical tersebut akan bersinergi dengan tujuan kebijakan moneter dalam mengurangi fluktuasi perekonomian (Arnold et al., 2012: 3127; Gersbach dan Rochet, 2012: 83). Secara operasional, sejumlah kajian telah dilakukan untuk mendesain kebijakan makroprudensial yang bersifat countercyclical (Bank of England 2011: 5; Arregui et al., 2012: 13; Buncic dan Martin, 2013: 356). Dalam konteks regulasi persyaratan modal, instrumen regulasi modal yang bersifat countercyclical adalah tambahan modal atau surcharge diatas modal minimum yang disyaratkan oleh regulasi mikroprudensial. Tambahan modal tersebut harus bersifat dinamis (time-varying capital surcharge), bervariasi secara countercyclical, meningkat ketika perekonomian sedang naik untuk mengerem pertumbuhan neraca bank dan turun ketika periode sedang melemah untuk memberikan insentif kepada bank untuk tetap menyalurkan kredit (Bank of England 2011: 8).

Penggunaan instrumen makroprudensial sebenarnya bukan hal yang baru, hanya saja instrumen tersebut lebih banyak diterapkan pasca krisis global tahun 2008. Penggunaan instrumen tersebut tergantung pada tingkat perkembangan ekonomi dan keuangan, rezim nilai tukar, dan daya tahan (kerentanan) terhadap guncangan (shocks) (Delgado dan Mynor, 2011: 28). Instrumen-instrumen tersebut sering kali digunakan secara komplemen dengan kebijakan makroekonomi lainnya, misalnya kebijakan moneter dan kebijakan fiskal, dan berfungsi sebagai automatic stabilizer.

Pada dasarnya instrumen kebijakan makroprudensial dapat dikelompokkan menjadi tiga bagian seperti pada Tabel 1.

\begin{tabular}{|c|c|c|}
\hline \multicolumn{3}{|c|}{$\begin{array}{c}\text { Tabel } 1 \\
\text { Instrumen Kebijakan Makroprudensial }\end{array}$} \\
\hline Masalah & Instrumen & Target \\
\hline Kredit & $\begin{array}{l}\text { 1. Caps on the loan-to-value (LTV) ratio } \\
\text { 2. Caps on the debt-to-income (DTI) ratio } \\
\text { 3. Caps on foreign currency lending } \\
\text { 4. Ceilings on credit or credit growth }\end{array}$ & $\begin{array}{l}\text { Prosiklikalitas } \\
\text { Prosiklikalitas } \\
\text { Prosiklikalitas } \\
\text { Prosiklikalitas }\end{array}$ \\
\hline Likuiditas & $\begin{array}{l}\text { 1. Limits on net open currency positions / currency } \\
\text { mismatch (NOP) } \\
\text { 2. Limits on maturity mismatch } \\
\text { 3. Reserve requirements }\end{array}$ & $\begin{array}{l}\text { Common exposure } \\
\text { Common exposure } \\
\text { Prosiklikalitas }\end{array}$ \\
\hline Modal & $\begin{array}{l}\text { 1. Countercyclical / time-varying capital requirements } \\
\text { 2. Time varying / dynamic provisioning } \\
\text { 3. Restrictions on profit distribution }\end{array}$ & $\begin{array}{l}\text { Prosiklikalitas } \\
\text { Prosiklikalitas } \\
\text { Prosiklikalitas }\end{array}$ \\
\hline
\end{tabular}

Sumber: IMF Financial Stability and Macroprudential Policy Survey, 2010 
Implementasi dari instrumen tersebut dilakukan dengan belajar dan mengaplikasikannya. Kalibrasinya dilakukan secara uji coba tergantung pada jenis guncangan yang dihadapi (Lima et al., 2012: 15). Dari sudut pandang Galati dan Richhild (2011: 27) dan CGFS (2010: 16-18), desain dan kalibrasi dari instrumen biasanya berdasarkan diskresi, bukan berdasarkan aturan. Instrumen makroprudensial tersebut digunakan dengan tingkat diskresi yang cukup dominan dibandingkan aturan dasar mengingat ketidakpastian yang tinggi dalam menjalankan kebijakan makroprudensial. Kelebihan dari diskresi ini adalah fleksibilitas yang tinggi dalam menjawab instrumen yang sesuai dengan pengalaman dan informasi yang didapat (Beau et al., 2012: 17). Model hanya digunakan untuk simulasi, sementara untuk penentuan besarnya tingkat instrumen dilakukan melalui diskresi (Tovar et al., 2012: 21). Tingkat efektivitas dari instrumen kebijakan ini masih dinilai tentatif mengingat penerapannya biasanya dilakukan bersamaan dengan kebijakan moneter.

Pada umumnya, instrumen kebijakan makroprudensial yang diterapkan di beberapa negara berbeda satu sama lain tergantung dari tingkat pertumbuhan ekonomi dan kondisi stabilitas sistem keuangan negara tersebut. Penelitian Hahm et al., (2009) di Korea Selatan menunjukkan bahwa kebijakan LTV, LDR, dan GWM sebagai instrumen makroprudensial sangat efektif untuk mengurangi siklus kredit. Sebaliknya, kebijakan yang ketat justru tidak efektif untuk mencegah terjadinya penggelembungan kredit. Mereka juga berpendapat bahwa penambahan tujuan dari kebijakan ini akan menjadikan kebingungan mengenai komitmen bank sentral pada kestabilan finansial.

Senada dengan penelitian yang dilakukan oleh Tovar et al., (2012) di Brazil, Kolumbia, dan Peru yang menunjukkan bahwa penggunaan instrumen makroprudensial berupa GWM efektif diterapkan di Brazil dan Peru, sedangkan di Kolumbia tidak efektif. Hal ini dikarenakan tingkat pertumbuhan kredit di Kolumbia relatif lebih kecil daripada di Brazil dan Peru serta adanya gap yang tinggi antara nilai tular mata uang dengan kredit yang diberikan oleh perbankan di negara tersebut.

Lain halnya penelitian yang dilakukan oleh Bustamante et al. (2012), yang meneliti efektifitas penggunaan instrumen makroprudensial berupa LTV di Kolumbia. Penelitiannya menunjukkan bahwa kebijakan LTV kurang efektif diterapkan karena naiknya harga rumah yang digunakan sebagai agunan pinjaman sehingga secara rata-rata dapat menurunkan rasio LTV dan akan menurunkan suku bunga pinjaman.

Kemudian, penelitian yang dilakukan oleh Lim et al. (2011) mengevaluasi efektifitas penggunaan instrumen makroprudensial dalam mengurangi risiko sistemik di 49 negara. Mereka berargumen bahwa sebagian besar instrumen (LTV dan GWM) efektif dalam mengurangi prosiklikalitas, tetapi efektivitasnya sangat tergantung pada goncangan di sektor finansial. 


\section{METODOLOGI}

Jenis data yang digunakan dalam penelitian ini adalah data sekunder berupa data runtut waktu dan data panel. Periode data yang digunakan adalah data bulanan dari kurun waktu 2004M1-2012M12. Sedangkan data antar ruang (cross section) adalah jenis bank di Indonesia, yaitu bank pemerintah, bank asing, bank campuran, bank swasta, dan bank pembangunan daerah. Unit analisis penelitian ini adalah bank umum di Indonesia. Data yang digunakan dalam penelitian ini diperoleh dari Statistik Ekonomi dan Moneter Indonesia (SEMI), Statistik Perbankan Indonesia (SPI), dan Statistik Ekonomi dan Keuangan Indonesia (SEKI), yang mana semua data tersebut dipublikasikan oleh Bank Indonesia.

Spesifikasi model yang digunakan dalam menjawab pertanyaan penelitian akan memodifikasi model penelitian yang dilakukan oleh Tovar et al. (2012), Hahm et al. (2011) dan Bustamante et al. (2012).

a. Model instrumen kebijakan month holding period (MHP)

$$
\begin{aligned}
V O L_{t}=\delta+ & \alpha_{1} V O L_{t-1}+\alpha_{2} G D P_{t-1}+\alpha_{3} I N F_{t-1}+\beta_{1} O M H P_{t}+\beta_{2} S M H P_{t} \\
& +\beta_{3} \text { KRISIS }_{t}+\beta_{4} O M H P * V O L_{t-1}+\beta_{5} S M H P * V O L_{t-1}+\varepsilon_{t} \\
N E R_{t}=\delta+ & \alpha_{1} N E R_{t-1}+\alpha_{2} G D P_{t-1}+\alpha_{3} I N F_{t-1}+\beta_{1} O M H P_{t}+\beta_{2} S M H P_{t} \\
& +\beta_{3} \text { KRISIS }_{t}+\beta_{4} O M H P * N E R_{t-1}+\beta_{5} S M H P * N E R_{t-1}+\varepsilon_{t}
\end{aligned}
$$

b. Model instrumen kebijakan Posisi Devisa Neto (PDN)

$$
\begin{gathered}
V O L_{t}=\delta+\alpha_{1} V O L_{t-1}+\alpha_{2} G D P_{t-1}+\alpha_{3} I N F_{t-1}+\beta_{1} P D N_{t}+\beta_{2} \text { KRISIS }_{t} \\
+\beta_{3} P D N * V O L_{t-1}+\varepsilon_{t} \\
N E R_{t}=\delta+\alpha_{1} N E R_{t-1}+\alpha_{2} G D P_{t-1}+\alpha_{3} I N F_{t-1}+\beta_{1} P D N_{t}+\beta_{2} \text { KRISIS }_{t} \\
+\beta_{3} P D N * N E R_{t-1}+\varepsilon_{t}
\end{gathered}
$$

c. Model instrumen kebijakan Giro Wajib Minimum (GWM)

$$
\begin{aligned}
\text { EKSES }_{t}=\delta & +\alpha_{1} \text { EKSES }_{t-1}+\alpha_{2} G D P_{t-1}+\alpha_{3} I N F_{t-1}+\beta_{1} G W M_{t}+\beta_{2} \text { KRISIS }_{t} \\
& +\beta_{3} G W M * E K S E S_{t-1}+\varepsilon_{t}
\end{aligned}
$$

d. Model instrumen kebijakan GWM + LDR (Loan to Deposit Ratio)

$$
\begin{aligned}
\operatorname{KREDIT}_{i t}= & \delta+\alpha_{1} \text { KREDIT }_{i t-1}+\alpha_{2} \text { SBDK }_{i t-1}+\alpha_{3} \text { BIRATE }_{i t-1} \\
& +\beta_{1} G W M L D R_{i t}+\beta_{2} \text { KRISIS }_{i t}+\beta_{3} G W M L D R * \text { Kredit }_{i t-1}+\varepsilon_{i t}
\end{aligned}
$$




\begin{tabular}{|c|c|c|}
\hline \multicolumn{3}{|c|}{$\begin{array}{c}\text { Tabel } 2 \\
\text { Definisi, Satuan, Sumber, serta Hipotesis Penelitian }\end{array}$} \\
\hline Variabel Endogen & Definisi -Satuan-Sumber & Hipotesis \\
\hline VOL & $\begin{array}{l}\text { - } \quad \text { Volatilitas nilai tukar yang dihitung berdasarkan } \\
\Delta \text { nilai tukar } \\
\text { - } \quad \text { Satuan : \% } \\
\text { - } \quad \text { Sumber: Bank Indonesia (diolah) }\end{array}$ & $\begin{array}{l}\text { Ho: Perubahan VOL tidak dipengaruhi oleh } \\
\text { perubahan kebijakan month holding period } \\
\text { (MHP) dan PDN } \\
\text { Ha: Perubahan VOL dipengaruhi oleh } \\
\text { perubahan kebijakan month holding period } \\
\text { (MHP) dan PDN }\end{array}$ \\
\hline NER & $\begin{array}{l}\text { - } \quad \text { Nilai tukar nominal adalah nilai yang digunakan } \\
\text { seseorang saat menukar mata uang suatu } \\
\text { negara dengan mata uang negara lain. } \\
\text { - } \quad \text { Satuan : Rp/USD } \\
\text { - } \quad \text { Sumber: Bank Indonesia }\end{array}$ & $\begin{array}{l}\text { Ho: Perubahan VOL tidak dipengaruhi oleh } \\
\text { perubahan kebijakan month holding period } \\
\text { (MHP) dan PDN } \\
\text { Ha: Perubahan VOL dipengaruhi oleh } \\
\text { perubahan kebijakan month holding period } \\
\text { (MHP) dan PDN }\end{array}$ \\
\hline GDP & $\begin{array}{l}\text { Gross Domestic Product Real yaitu nilai barang } \\
\text { dan jasa yang dihasilkan suatu negara dalam suatu } \\
\text { tahun dinilai menurut harga yang berlaku pada } \\
\text { suatu tahun tertentu yang seterusnya digunakan } \\
\text { untuk menilai barang dan jasa yang dihasilkan } \\
\text { pada tahun-tahun lain (US\$). } \\
\text { - } \quad \text { Satuan : Rupiah } \\
\text { - } \quad \text { Sumber: Bank Indonesia }\end{array}$ & $\begin{array}{l}\text { Ho: GDP tidak mempengaruhi perubahan VOL. } \\
\text { Ha: GDP mempengaruhi perubahan VOL }\end{array}$ \\
\hline INF & $\begin{array}{l}\text { Inflasi adalah suatu keadaan dimana harga barang } \\
\text { secara umum mengalami kenaikan secara terus } \\
\text { menerus. Tingkat inflasi berdasarkan IHK. } \\
\text { - } \quad \text { Satuan : \% } \\
\text { - } \quad \text { Sumber: Bank Indonesia }\end{array}$ & $\begin{array}{l}\text { Ho: INF tidak mempengaruhi perubahan VOL. } \\
\text { Ha: INF mempengaruhi perubahan VOL }\end{array}$ \\
\hline SBDK & $\begin{array}{l}\text { Suku Bunga Dasar Kredit adalah suku bunga dasar } \\
\text { yang digunakan oleh bank sebagai acuan dalam } \\
\text { penentuan suku bunga kredit rupiah kepada debitur. } \\
\text { - } \quad \text { Satuan : \% } \\
\text { - } \quad \text { Sumber: Bank Indonesia }\end{array}$ & $\begin{array}{l}\text { Ho: SBDK tidak mempengaruhi perubahan } \\
\text { Kredit. } \\
\text { Ha: SBDK mempengaruhi perubahan Kredit }\end{array}$ \\
\hline KREDIT & $\begin{array}{l}\text { Seluruh volume kredit yang disalurkan oleh bank } \\
\text { - Satuan : Rupiah } \\
\text {-Sumber: Bank Indonesia }\end{array}$ & $\begin{array}{l}\text { Ho: Perubahan Kredit tidak dipengaruhi oleh } \\
\text { perubahan kebijakan GWM+LDR. } \\
\text { Ha: Perubahan Kredit dipengaruhi oleh } \\
\text { perubahan kebijakan GWM+LDR. }\end{array}$ \\
\hline BIRATE & $\begin{array}{l}\text { Tingkat suku bunga acuan yang dikeluarkan oleh } \\
\text { Bank Indonesia } \\
\text {-Satuan : \% } \\
\text {-Sumber: Bank Indonesia }\end{array}$ & $\begin{array}{l}\text { Ho: BIRATE tidak mempengaruhi perubahan } \\
\text { Kredit. } \\
\text { Ha: BIRATE mempengaruhi perubahan Kredit }\end{array}$ \\
\hline
\end{tabular}




\begin{tabular}{|c|c|c|}
\hline \multicolumn{3}{|c|}{$\begin{array}{c}\text { Tabel } 2 \\
\text { Definisi, Satuan, Sumber, serta Hipotesis Penelitian }\end{array}$} \\
\hline Variabel Endogen & Definisi -Satuan-Sumber & Hipotesis \\
\hline OMHP & $\begin{array}{l}\text { Dummy kebijakan month holding period (MHP) } 1 \\
\text { bulan } \\
D=0 \text {, sebelum kebijakan diterapkan } \\
D=1 \text {, setelah kebijakan diterapakan }\end{array}$ & $\begin{array}{l}\text { Ho: OMHP tidak efektif diterapkan } \\
\text { Ha: OMHP efektif diterapkan }\end{array}$ \\
\hline SMHP & $\begin{array}{l}\text { Dummy kebijakan month holding period (MHP) } 6 \\
\text { bulan } \\
D=0 \text {, sebelum kebijakan diterapkan } \\
D=1 \text {, setelah kebijakan diterapakan }\end{array}$ & $\begin{array}{l}\text { Ho: SMHP tidak efektif diterapakn } \\
\text { Ha: SMHP efektif diterapkan }\end{array}$ \\
\hline PDN & $\begin{array}{l}\text { Dummy kebijakan PDN } \\
D=0 \text {, sebelum kebijakan diterapkan } \\
D=1, \text { setelah kebijakan diterapakan }\end{array}$ & $\begin{array}{l}\text { Ho: PDN tidak efektif diterapakn } \\
\text { Ha: PDN efektif diterapkan }\end{array}$ \\
\hline GWM & $\begin{array}{l}\text { Dummy kebijakan GWM } \\
D=0 \text {, sebelum kebijakan diterapkan } \\
D=1 \text {, setelah kebijakan diterapakan }\end{array}$ & $\begin{array}{l}\text { Ho: GWM tidak efektif diterapakn } \\
\text { Ha: GWM efektif diterapkan }\end{array}$ \\
\hline GWM+LDR & $\begin{array}{l}\text { Dummy kebijakan GWM+LDR } \\
D=0, \text { sebelum kebijakan diterapkan } \\
D=1, \text { setelah kebijakan diterapakan }\end{array}$ & $\begin{array}{l}\text { Ho: GWM+LDR tidak efektif diterapakn } \\
\text { Ha: GWM+LDR efektif diterapkan }\end{array}$ \\
\hline KRISIS & $\begin{array}{l}\text { Dummy krisis } 2008 \\
D=0 \text {, sebelum krisis } 2008 \\
D=1 \text {, setelah krisis } 2008\end{array}$ & $\begin{array}{l}\text { Ho: KRISIS tidak mempengaruhi perubahan } \\
\text { VOL } \\
\text { Ha: KRISIS mempengaruhi perubahan VOL }\end{array}$ \\
\hline
\end{tabular}

Alat analisis yang digunakan untuk menjawab pertanyaan penelitian pertama adalah event analysis. Event analysis merupakan alat untuk mengukur efek pergerakan sasaran instrumen kebijakan makroprudensial sebelum dan setelah kebijakan tersebut diimplementasikan (Tovar et al., 2012). Kemudian untuk melihat siklus sasaran komponen kebijakan akan digunakan besaran nilai rata-rata yang akan menunjukkan pergerakannya prosiklikalitas atau countercyclical.

Alat analisis yang digunakan dalam menjawab pertanyaan yang kedua adalah Vector Autoregressive Exogenous. VARX merupakan pengembangan dari model VAR yang menggunakan variabel eksogen dalam sistem persamaannya (Bierens, 2004; Horvath et al., 2005). Banyak situasi dimana proses vektor variabel endogen tidak hanya sebagai hasil dari input stokastik murni, tetapi juga tergantung pada input yang dikontrol. Variabel eksogen dalam model VARX dapat juga disebut sebagai variabel independen, input, prediktor, atau regresor. Variabel eksogen ditentukan di luar model dan bersifat mempengaruhi variabel endogen dalam suatu sistem persamaan (Biorn, 2011). Sedangkan variabel dependen, respon, atau endogen merupakan variabel yang ditentukan di dalam model dan dapat dipengaruhi oleh variabel eksogen atau variabel endogen yang lain. Prosedur VARX dapat digunakan untuk mencari pemodelan dan hubungan dinamis antara variabel endogen dengan variabel eksogen (Cui dan Angsar, 2008). 


\section{HASIL DAN ANALISIS}

\subsection{Kebijakan Month Holding Period}

Hasil event analysis pada Grafik 2 menunjukkan bahwa semenjak kebijakan one month holding period diumumkan pada Mei 2010 dan diterapkan pada Juni 2010 kondisi volatilitas nilai tukar bergerak relatif stabil dari nilai rata-rata bergerak volatilitas tukar 5 bulan. Sehingga kondisi prosiklikalitas yang terjadi sebelum periode penerapan kebijakan OMHP dapat dimitigasi. Tujuan kebijakan makroprudensial yang bersifat countercyclical tercapai dengan kebijakan OMHP. Perbedaan terjadi ketika kebijakan SMHP diterapkan pada Mei 2011. Setelah sasaran kebijakan makroprudensial yang bersifat countercyclical tercapai, ternyata kebijakan SMHP menimbulkan prosiklikalitas pada volatilitas nilai rupiah.

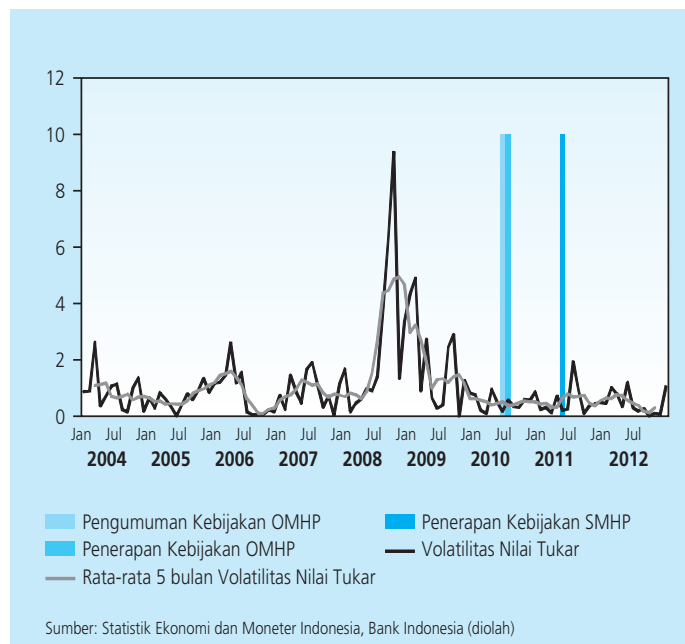

Grafik 2. Event Analysis Dampak Kebijakan MHP terhadap Volatilitas Nilai Tukar

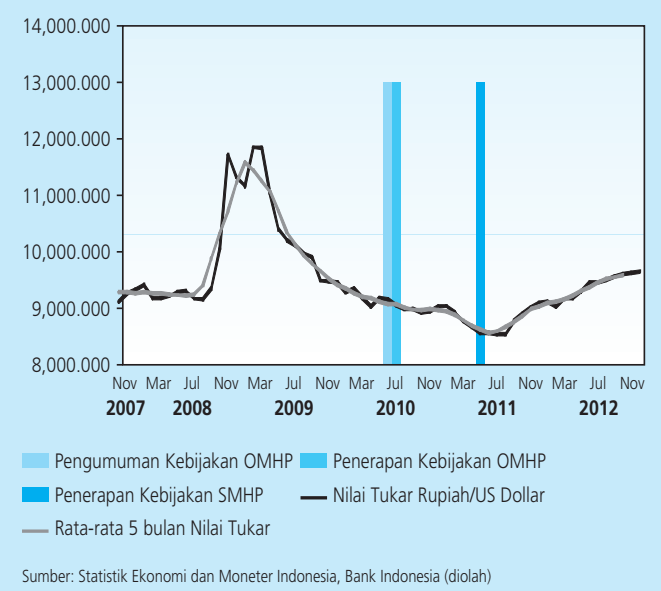

Grafik 3. Event Analysis Dampak Kebijakan MHP terhadap Nilai Tukar Rupiah terhadap Dolar Amerika 
Grafik 3 menunjukkan bahwa semenjak kebijakan one month holding period diumumkan pada Mei 2010 kondisi nilai tukar bergerak relatif stabil dari nilai rata-rata bergeraknya, dan cenderung rupiah terapresiasi. Sehingga kondisi prosiklikalitas nilai tukar rupiah akibat adanya krisis 2008 dapat dimitigasi. Akan tetapi, semenjak BI mengeluarkan kebijakan SMHP pada Mei 2011, kondisi nilai tukar mengalami depresiasi meskipun tidak terjadi prosiklikalitas.

Hasil analisis VARX pada Tabel 3. menunjukkan bahwa kebijakan OMHP sebagai dummy konstanta secara signifikan mempengaruhi volatilitas nilai tukar dan mempunyai hubungan yang positif, begitu juga ketika kebijakan OMHP berinteraksi dengan volatilitas nilai tukar sebelumnya. Hasil yang berbeda ditunjukkan oleh kebijakan SMHP yang mana sebagai dummy konstanta tidak signifikan mempengaruhi volatilitas nilai tukar, akan tetapi ketika berinteraksi dengan volatilitas nilai tukar sebelumnya, kebijakan SMHP secara signifikan mempengaruhi volatilitas nilai tukar.

\begin{tabular}{|c|c|c|}
\hline \multicolumn{3}{|c|}{$\begin{array}{c}\text { Tabel } 3 \\
\text { Hasil VARX Dampak Kebijakan month holding period (MHP) terhadap Volatilitas Nilai Tukar }\end{array}$} \\
\hline \multirow{2}{*}{ Variabel } & \multicolumn{2}{|c|}{ VARX (t-statistik) } \\
\hline & Dummy konstanta & Dummy Interaksi \\
\hline $\operatorname{GDP}(-1)$ & $-3.61739^{\star}$ & $-3.64955^{*}$ \\
\hline INFLASI(-1) & 0.19998 & 0.21556 \\
\hline $\operatorname{VOL}(-1)$ & $3.72229^{\star}$ & $3.68787^{*}$ \\
\hline C & $-2.87020^{*}$ & $-2.96171^{*}$ \\
\hline OMHP & $2.82314^{*}$ & \\
\hline SMHP & -1.49891 & \\
\hline OMHP*VOL(-1) & & $3.25171^{*}$ \\
\hline SMHP*VOL(-1) & & $-3.49142^{*}$ \\
\hline KRISIS & $-2.91387^{*}$ & $-2.96255^{\star}$ \\
\hline R-squared & 0.899445 & 0.951175 \\
\hline F-Stat & 84.97536 & 185.0728 \\
\hline
\end{tabular}

Tabel 4. menunjukkan bahwa kebijakan OMHP sebagai dummy konstanta secara signifikan mempengaruhi nilai tukar dan mempunyai hubungan yang positif, akan tetapi ketika berinteraksi dengan nilai tukar sebelumnya, kebijakan OMHP tidak signifikan mempengaruhi nilai tukar. Hasil lain ditunjukkan oleh kebijakan SMHP yang mana sebagai dummy konstanta dan dummy interaksi, keduanya tidak signifikan mempengaruhi nilai tukar, akan tetapi mempunyai hubungan yang positif.

Dari hasil event analysis yang diperkuat dengan uji ekonometrik analisis VARX, terlihat bahwa kebijakan month holding period (MHP), baik itu OMHP maupun SMHP, mempunyai dampak yang signifikan dalam menurunkan volatilitas nilai tukar. Namun demikian, kebijakan 


\begin{tabular}{|c|c|c|}
\hline \multicolumn{3}{|c|}{$\begin{array}{l}\text { Tabel } 4 \\
\text { Hasil VARX Dampak Kebijakan month holding period (MHP) terhadap Nilai Tukar }\end{array}$} \\
\hline \multirow{2}{*}{ Variabel } & \multicolumn{2}{|c|}{ VARX (t-statistik) } \\
\hline & Dummy konstanta & Dummy Interaksi \\
\hline GDP $(-1)$ & -0.12623 & $-4.58678^{\star \star}$ \\
\hline INFLASI (-1) & $-2.32282^{\star *}$ & 1.07772 \\
\hline $\operatorname{ER}(-1)$ & $11.8590^{\star}$ & $11.8780^{*}$ \\
\hline C & $3.87971^{*}$ & $3.80756^{*}$ \\
\hline OMHP & $2.19000^{* *}$ & \\
\hline SMHP & 0.49764 & \\
\hline OMHP*NER(-1) & & $-1.81583^{* * *}$ \\
\hline SMHP*NER(-1) & & 0.58160 \\
\hline KRISIS & $2.26461^{* *}$ & $2.06340^{* *}$ \\
\hline R-squared & 0.886139 & 0.885581 \\
\hline F-Stat & 83.01459 & 82.55813 \\
\hline
\end{tabular}

month holding period (MHP) tidak mempunyai dampak yang signifikan terhadap pergerakan nilai tukar. Hal ini bertolak belakang dengan penelitian yang dilakukan oleh Bustamente et al., (2012) di Kolombia yang menyatakan bahwa kebijakan time-varying capital requirements tidak efektif diterapkan di Kolumbia. Tetapi hasil penelitian ini senada dengan penelitian yang dilakukan oleh Bruno dan Hyun (2013) di Korea Selatan. Dalam penelitiannya menyebutkan bahwa dengan adanya kebijakan makroprudensial, aliran modal masuk yang deras dapat ditekan akibat kondisi nilai tukar yang stabil.

\subsection{Kebijakan Posisi Devisa Neto}

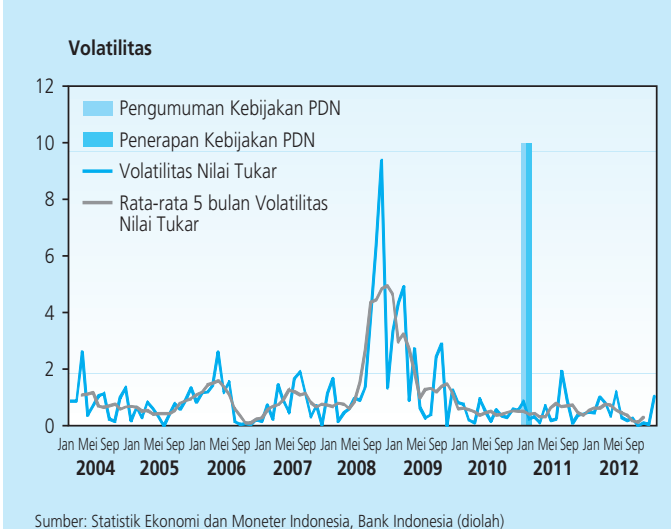

Grafik 4. Event Analysis Dampak Kebijakan PDN terhadap Volatilitas Nilai Tukar

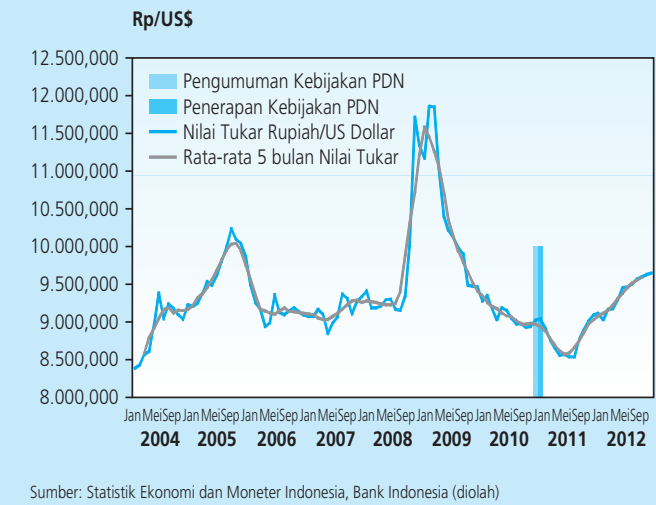

Grafik 5. Event Analysis Dampak Kebijakan PDN terhadap Nilai Tukar 
Grafik 4 dan 5 menunjukkan bahwa semenjak kebijakan posisi devisa neto (PDN) diumumkan pada Januari 2011 kondisi volatilitas nilai tukar dan nilai tukar nominal bergerak relatif stabil dari nilai rata-rata bergeraknya, dan cenderung rupiah terapresiasi. Sehingga kondisi prosiklikalitas akibat adanya krisis 2008 dapat dimitigasi.

\begin{tabular}{l|c|c}
\multicolumn{3}{c}{ Hasil VARX Dampak Kebijakan PDN terhadap Volatilitas Nilai Tukar } \\
\cline { 2 - 3 } \multicolumn{1}{c}{ Variabel } & \multicolumn{2}{|c}{ VARX (t-statistik) } \\
\cline { 2 - 3 } GDP $(-1)$ & Dummy konstanta & Dummy Interaksi \\
INFLASI (-1) & -0.60867 & -0.75304 \\
VOL (-1) & 0.20295 & 0.22277 \\
C & $3.81822^{*}$ & $4.05798^{*}$ \\
PDN & $2.72845^{*}$ & $1.67866^{* * *}$ \\
PDN*VOL(-1) & $3.46375^{*}$ & \\
KRISIS & & $3.34849^{*}$ \\
R-squared & $2.96943^{*}$ & $2.64538^{*}$ \\
F-Stat & 0.952252 & 0.894465 \\
\hline Signifikan pada level of significant* $1 \%,{ }^{* *} 5 \%,{ }^{* * *} 10 \%$ & & 80.51734 \\
\hline
\end{tabular}

\begin{tabular}{l|c|c}
\multicolumn{3}{c}{ Hasil VARX Dampak Kebijakan PDN terhadap Volatilitas Nilai Tukar } \\
\cline { 2 - 3 } \multicolumn{1}{c|}{ Variabel } & \multicolumn{2}{|c}{ VARX (t-statistik) } \\
\cline { 2 - 3 } GDP(-1) & 0.85512 & Dummy Interaksi \\
INFLASI(-1) & 0.77008 & 1.28895 \\
NER $(-1)$ & $12.1381^{*}$ & 0.76672 \\
C & $3.48176^{*}$ & $12.1372^{*}$ \\
PDN & $4.69202^{*}$ & $3.44904^{*}$ \\
PDN*NER(-1) & & \\
KRISIS & $4.97141^{*}$ & $3.98345^{*}$ \\
R-squared & 0.882514 & $3.59807^{*}$ \\
F-Stat & 91.07920 \\
\hline Signifikan pada level of significant* $1 \%,{ }^{* *} 5 \%,{ }^{* * *} 10 \%$ & \\
\hline
\end{tabular}

Tabel 5 menunjukkan bahwa kebijakan PDN sebagai dummy konstanta secara signifikan mempengaruhi volatilitas nilai tukar dan mempunyai hubungan yang positif, begitu juga ketika kebijakan PDN berinteraksi dengan volatilitas nilai tukar sebelumnya. Hasil yang sama juga ditunjukkan pada tabel 6 bahwa kebijakan PDN sebagai dummy konstanta secara signifikan memengaruhi nilai tukar nominal dan mempunyai hubungan yang positif, begitu juga ketika kebijakan PDN berinteraksi dengan nilai tukar sebelumnya. 
Hasil event analysis maupun analisis VARX, terlihat bahwa kebijakan PDN secara signifikan berdampak menurunkan volatilitas nilai tukar. Namun demikian, kebijakan PDN tidak signifikan dampaknya terhadap pergerakan nilai tukar. Hasil penelitian ini berbeda dengan penelitian yang dilakukan oleh Bruno dan Hyun (2013) di Korea Selatan. Dalam penelitiannya menyebutkan bahwa kebijakan net open position secara signifikan mempengaruhi nilai tukar nominal. Ketika kebijakan ini diterapkan, perilaku perbankan di Korea Selatan dalam melakukan aliran modal sangat besar, sehingga perilaku nilai tukar mata uang dikendalikan agar aliran modal masuk tidak terlalu deras.

\subsection{Kebijakan Giro Wajib Minimum}

Di tengah terbatasnya ruang kebijakan suku bunga, BI menerapkan kebijakan GWM Primer untuk menyerap kondisi ekses likuiditas tersebut. Dengan mengenakan rasio 8\% dari DPK Rupiah, kebijakan GWM Primer dipandang cukup mampu untuk menyerap ekses likuiditas.

Grafik 6 menunjukkan bahwa semenjak kebijakan giro wajib minimum primer diumumkan pada November 2010 kondisi operasi pasar terbuka bergerak mengikuti arah gerak rata-rata dan cenderung berfluktuasi. Sehingga kondisi prosiklikalitas masih terjadi ketika kebijakan GWM primer diterapkan. Meskipun efektivitas kebijakan GWM Primer tersebut dipandang kurang efektif disebabkan oleh kondisi ekses likuiditas yang sudah tinggi ditambah dengan aliran modal masuk yang besar dan tercermin dari posisi operasi pasar terbuka yang masih cenderung meningkat, meskipun pada akhir 2011 kondisinya menurun.

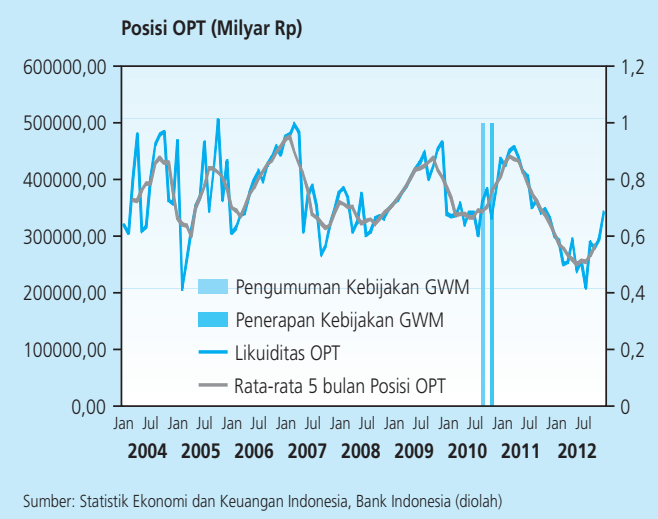

Grafik 6. Event Analysis Dampak Kebijakan GWM terhadap Posisi Operasi Pasar Terbuka 


\begin{tabular}{l|c|c}
\multicolumn{3}{c}{ Hasil VARX Dampak Kebijakan GWM terhadap Ekses Likuiditas } \\
\cline { 2 - 3 } \multicolumn{1}{c|}{ Variabel } & \multicolumn{2}{|c}{ VARX (t-statistik) } \\
\cline { 2 - 3 } EKSES(-1) & 0.52297 & Dummy Interaksi \\
GDP(-1) & $8.94819^{*}$ & -0.43497 \\
INFLASI(-1) & $1.68209^{* * *}$ & $2.65582^{*}$ \\
C & $3.48459^{*}$ & -0.18558 \\
KRISIS & $2.17821^{* *}$ & $4.00726^{*}$ \\
GWM & 0.32070 & $2.42455^{* *}$ \\
GWM*EKSES(-1) & & \\
R-squared & 0.455128 & 1.32149 \\
F-Stat & 10.12795 & 0.464197 \\
\hline Signifikan pada level of significant* $1 \%,{ }^{* *} 5 \%,{ }^{* * *} 10 \%$ & \\
\hline
\end{tabular}

Tabel 7 menunjukkan bahwa kebijakan GWM sebagai dummy konstanta tidak signifikan mempengaruhi ekses likuiditas, akan tetapi mempunyai hubungan yang positif. Hasil estimasi kebijakan PDN ketika berinteraksi dengan ekses likuiditas sebelumnya juga tidak signifikan mempengaruhi ekses likuiditas, tetapi juga mempunyai hubungan yang positif. Kemungkinan besarnya ekses likuiditas dipengaruhi oleh faktor lain di luar model kebijakan GWM, karena model ini ketika diestimasi dengan VARX mempunyai nilai $R^{2}$ yang rendah, baik itu dengan adanya dummy konstanta maupun dummy interaksi.

Berdasarkan hasil analisis dari event analysis dan VARX, pengaruh kebijakan GWM Primer terhadap ekses likuiditas menunjukkan bahwa dampak kebijakan GWM Primer bersifat temporer dan juga terbatas terhadap kondisi ekses likuiditas perbankan. Kondisi ini tidak terlepas dari besarnya ekses likuiditas yang telah ada di sektor perbankan serta arus masuk modal asing yang juga sangat besar. Akibatnya, shock kenaikan kebijakan GWM Primer relatif tidak terlalu banyak pengaruhnya terhadap pengurangan ekses likuiditas. Kondisi ini juga sejalan dengan event analysis dimana pasca berlakunya kebijakan GWM Primer, posisi ekses likuiditas yang diserap melalui OPT juga masih terus meningkat. Sehingga kebijakan ini tidak efektif diterapakan.

Berbeda dengan penelitian yang dilakukan oleh Tovar et al., (2012) di Brazil, Kolumbia, dan Peru yang menunjukkan bahwa penggunaan instrumen makroprudensial berupa GWM efektif diterapkan di Brazil dan Peru, sedangkan di Kolumbia tidak efektif. Penelitian yang dilakukan oleh Bustamante., et al (2012) di Kolumbia juga menghasilkan hasil penelitian yang sama dengan penelitian ini. Kebijakan giro wajib minimum (reserve requirement) di Kolumbia tidak efektif diterapkan karena kondisi ekses likuiditas di negara tersebut sangat berfluktuasi. 


\subsection{Kebijakan Giro Wajib Minimum + Loan to Deposit Ratio}

Hasil event analysis menunjukkan bahwa pengumuman kebijakan GWM LDR mempunyai dampak yang signifikan terhadap peningkatan kredit terutama pada kategori bank swasta, pemerintah, dan pembangunan daerah. Pada jenis bank campuran dan bank asing, terlihat penurunan kredit pada masa transisi. Namun demikian, total kredit kelima jenis bank tersebut mempunyai kecenderungan untuk kembali meningkat sejak penerapan kebijakan LDR+GWM. Penyesuaian dan peningkatan kondisi kredit perbankan juga terus berlangsung beberapa periode setelah diberlakukannya kebijakan dan cenderung stabil pada periode selanjutnya.

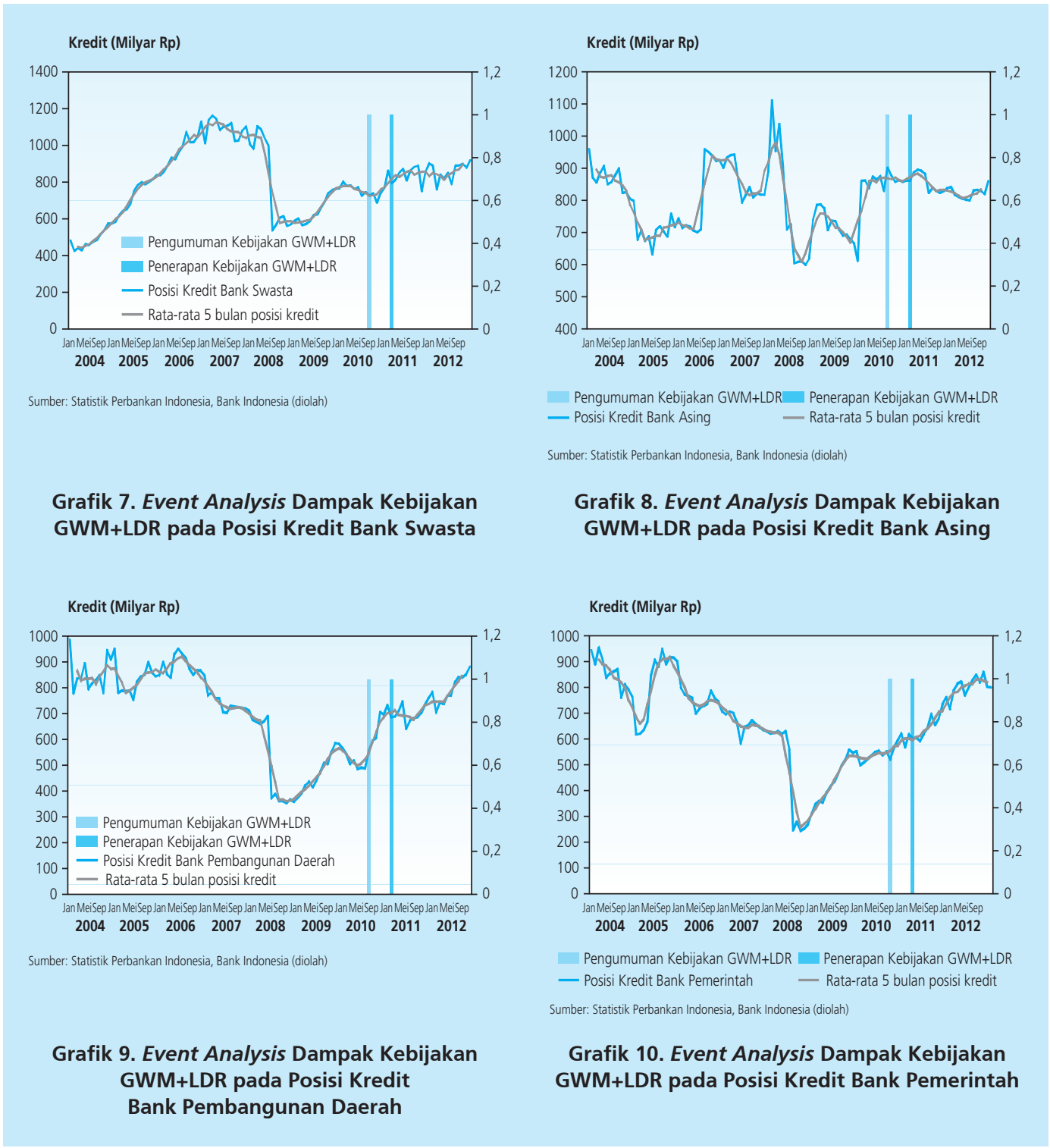




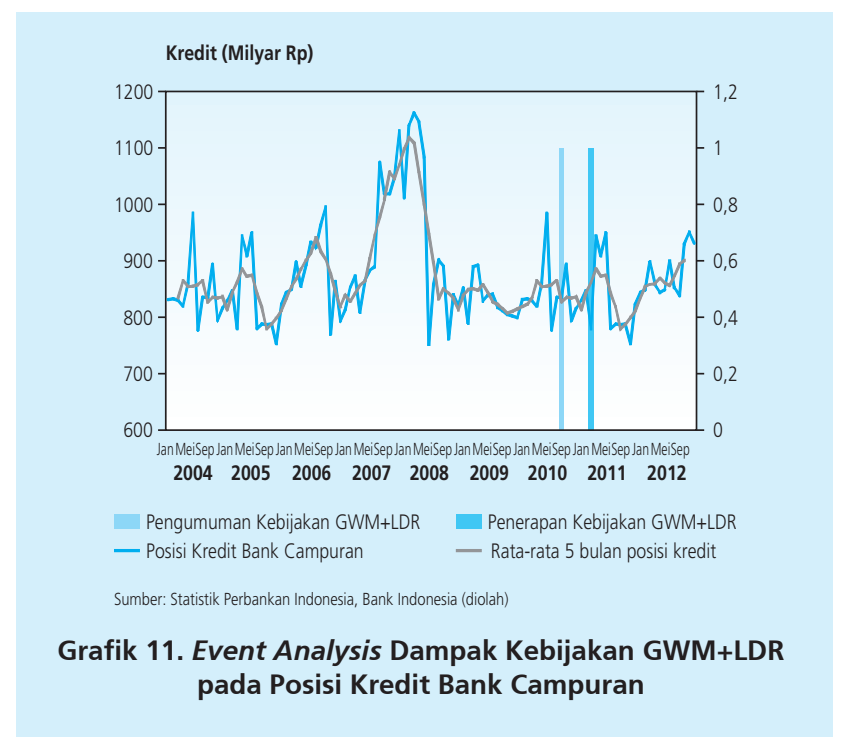

Setelah dikeluarkannya kebijakan GWM+LDR, sebagaimana telah diperkirakan sebelumnya, dampak kebijakan ini bersifat kontraktif di awal. Hal ini terlihat dari penurunan pertumbuhan kredit dalam 3 bulan pada masing- masing jenis bank setelah implementasi kebijakan GWM+LDR. Kemudian, pada bulan-bulan berikutnya, pertumbuhan kredit kembali normal dan bahkan terus meningkat. Meskipun berdasarkan grafik tersebut, hasilnya menunjukkan bahwa implementasi GWM+LDR terkait dengan penurunan pertumbuhan kredit, namun hal ini bisa juga dikarenakan oleh sinkronisasi antara kebijakan pengetatan GWM dengan kenaikan suku bunga BI rate. Oleh karena itu, event analysis tidak memungkinkan untuk memisahkan efek yang benar-benar berasal dari kebijakan GWM ataukah berasal dari shock kebijakan suku bunga.

Temuan berdasarkan analisis VARX ini juga sejalan dengan event analysis, meskipun pada awalnya pertumbuhan kredit sempat mengalami kontraksi namun selanjutnya kembali ke level pertumbuhan semula. Dengan kata lain, kebijakan GWM+LDR relatif berdampak terhadap upaya untuk mendorong kredit bank secara keseluruhan. Hal ini ditunjukkan dari hasil analisis VARX pada Tabel 8. Begitu juga ketika kebijakan GWM+LDR berinteraksi dengan kredit sebelumnya yang menunjukkan bahwa dampak interaksi kebijakan GWM+LDR signifikan mendorong pertumbuhan kredit yang dilakukan semua jenis bank. 


\begin{tabular}{|c|c|c|}
\hline \multicolumn{3}{|c|}{$\begin{array}{c}\text { Tabel } 8 \\
\text { Hasil VARX Dampak Kebijakan GWM LDR terhadap Total Kredit }\end{array}$} \\
\hline \multirow{2}{*}{ Variabel } & \multicolumn{2}{|c|}{ VARX (t-statistik) } \\
\hline & Dummy konstanta & Dummy Interaksi \\
\hline Kredit(-1) & $12.4261^{*}$ & $12.3882^{*}$ \\
\hline $\operatorname{SBDK}(-1)$ & 1.59229 & -1.55958 \\
\hline BI Rate(-1) & 0.55321 & 0.55425 \\
\hline C & $3.71444^{*}$ & $3.81865^{*}$ \\
\hline GWM LDR & $2.69083^{*}$ & \\
\hline GWM LDR*Kredit (-1) & & $3.59555^{*}$ \\
\hline KRISIS & 0.27105 & -0.41389 \\
\hline R-squared & 0.724843 & 0.725262 \\
\hline F-statistic & 170.5701 & 170.9293 \\
\hline
\end{tabular}

Kesimpulan bahwa kebijakan GWM+LDR relatif berdampak terhadap upaya untuk mendorong kredit bank secara keseluruhan sama dengan kesimpulan penelitian yang dilakukan Hahm et al., (2007) di Korea Selatan. Hasil penelitiannya menunjukkan bahwa kebijakan LDR sebagai instrumen makroprudensial sangat efektif untuk mengurangi siklus kredit. Sebaliknya, kebijakan yang ketat justru tidak efektif untuk mencegah terjadinya penggelembungan kredit. Mereka juga berpendapat bahwa penambahan tujuan dari kebijakan ini akan menjadikan kebingungan mengenai komitmen bank sentral pada kestabilan finansial.

\section{KESIMPULAN}

Paper ini menganalisis peran kebijakan makroprudensial dalam perekonomian Indonesia. Berdasarkan event analysis, dapat diketahui bahwa pergerakan sasaran komponen kebijakan makroprudensial yang dilakukan Bank Indonesia pasca krisis keuangan 2008 relatif mengikuti pergerakan rata-rata kondisi perekonomian, terutama untuk menjaga volatilitas nilai tukar rupiah dan mendorong kebijakan GWM+LDR yang optimal dalam pengelolaan risiko kredit. Analisis dalam paper ini secara umum menemukan bahwa kebijakan makroprudential Bank Indonesia sebagian besar efektif.

Temuan pertama yang dapat menjadi kesimpulan dalam paper ini adalah bahwa tingkat volatilitas nilai tukar menurun setelah penerapan kebijakan one month holding, six month holding, dan Posisi Devisa Neto. Pasca pengumuman dan penerapan kebijakan one month holding period (OMHP) dan posisi devisa netto (PDN), volatilitas nilai tukar dan nilai tukar Rupiah terhadap Dolar Amerika sudah tidak bersifat prosiklikal, tetapi pasca penerapan kebijakan six month holding period (SMHP), terjadi prosiklikalitas pada volatilitas nilai tukar. Namun demikian, 
perlu digarisbawahi bahwa terhadap nilai tukar nominal, kebijakan-kebijakan tersebut tidak efektif.

Kedua, Secara aggregat kebijakan GWM LDR efektif dalam menaikkan kredit bank. Namun demikian, dampak kebijakan ini bervariasi lintas jenis bank.Untuk bank asing dan campuran kebijakan ini tidak efektif. Analisa event menunjukkan pergerakan kredit di bank pemerintah, bank asing, dan bank swasta cenderung meningkat dan tidak bersifat prosiklikal. Pada sisi lain, pergerakan kredit pada bank pembangunan daerah dan bank campuran bersifat sangat fluktuatif dan menunjukkan prosiklikalitas, baik setelah pengumuman maupun kebijakan makropurdensial itu diterapkan.

Ketiga, dampak kebijakan GWM primer sangat terbatas dalam menurunkan likuiditas perekonomian mengingat pada saat yang bersamaan arus modal asing yang masuk sangat deras. Lebih lanjut, event analysis yang dilakukan menunjukkan bahwa pergerakan likuiditas bank tidak menunjukkan prosiklikalitas setelah pengumuman dan penerapan kebijakan GWM primer.

Berdasarkan tiga kesimpulan di atas, maka rekomendasi kebijakan yang dapat diterapkan adalah kebijakan yang memberikan disinsentif bagi arus modal yang berjangka pendek. Kewajiban hedging atas arus modal merupakan langkah-langkah yang dapat diterapkan untuk memperpanjang jangka waktu arus modal masuk. Selain itu, pembatasan GWM bank perlu dikaji lebih lanjut karena setelah kebijakan tersebut diterapakan masih ada beberapa persoalan mengenai likuiditas bank yang cenderung tidak stabil dan tingkat pertumbuhan ekses likuiditas yang semakin tinggi.

Mengacu pada analisis efektifitas instrumen kebijakan makroprudensial (month holding period, posisi devisa neto, giro wajib minimum, dan giro wajib minimum+ loan to deposit ratio) yang telah diterapkan di Indonesia, maka paradigma bahwa kebijakan moneter perlu didukung oleh kebijakan makroprudensial agar dapat berjalan secara efektif,membawa konsekuensi tidak dapat dipisahkannya kedua kebijakan ini dalam institusi yang berbeda. Dalam konteks ini, apabila fungsi pengawasan perbankan dipisahkan dari Bank Indonesia, kerangka kebijakan makroprudensial tidak bisa dihindari dan harus melibatkan dua institusi, yaitu BI dan OJK. Jalan terbaik adalah BI diberikan mandat makroprudensial sedangkan OJK diberikan mandat mikroprudensial. Dalam konteks ini, BI berperan dalam melakukan pengawasan risiko sistem keuangan secara keseluruhan dan dapat melakukan regulasi dan tindakan yang dapat menyebabkan risiko sistemik. 


\section{DAFTAR PUSTAKA}

Agung, Juda. 2010. Mengintegrasikan Kebijakan Moneter dan Makroprudensial: Menuju Paradigma Baru Kebijakan Moneter di Indonesia Pasca Krisis Global. Working Paper, No. 07. Bank Indonesia.

Angelini, Paolo, Stefano Neri , dan Fabio Panetta. 2012. Monetary and Macroprudential Policies. Working Paper Series, No 1449, European Central Bank, Juli.

Arnold, Bruce, Claudio Borio, Luci Ellis, dan Fariborz Moshirian. 2012. Syatemic Risk,

Macroprudential Policy Frameworks, Monitoring Financial System, and the Evolution of Capital Adequacy. Journal of Banking and Finance, vol.36: 3125-3132.

Arregui, Nicolas, Jaromir Banes, Ivo Krznar, Srobona Mitra, dan Andre Oliveira Santos. 2013.

Evaluating the Net Benefit of Macroprudential Policy: A Cookbook. IMF Working Paper, WP/13/167.

Bank of England. 2009. The Role of Macroprudential Policy. A Discussion Paper, November. 2011. Instrument of Macroprudential Policy. A Discussion Paper, Desember

Beau, Denis, Laurent Clerc dan Benoit Mojon. 2012. Macro-Prudential Policy and the Conduct of Monetary Policy. Banque de France Working Paper, No.390, Juli.

Bierens, Herman J.. 2004. VAR Models with Exogenous Variables.

http://www.econ.psu.edu/ hbierens/EasyRegTours/VAR Tourfiles/VARX.PDF, diunduh Februari 2014

Biorn, Erik. 2011. Estimation of ARX and VARX Models by ML. Advanced Econometrics-Time Series, Lecture note No. 6, Februari.

Bruno, Valentina dan Hyun Song Shin. 2013. Assessing Macroprudential Policies: Case of Korea. Prepared for the Symposium Issue of the Scandinavian Journal of Economics on Capital Flow, April.

Buncic, Daniel, dan Martin Melecky. 2013. Macroprudential Stress Testing of Credit Risk: A Practical Approach for Policy Makers. Journal of Financial Stabilty, No. 9: 347-370.

Bustamante, C., Gonzales, A., dan Perez, J. 2012. Macroprudential Policy, External Shocks and Financial Intermediation on a Small Open Economy. Borradores de Economica, No. 716 I.

Claessens, Stijn dan Swati R. Ghosh. 2012. Macro-Prudential Policies: Lesson for and from Emerging Markets. Prepared for the East-West Center and the Korea Development Institute Conference, Juli. 
Claessens, Stijn, Swati R. Ghosh, dan Roxana Mihet. 2012. Macro-Prudential Policies to Mitigate Financial System Vulnerabilities. Prepared for the NIPFP-DEA-JIMF conference Rajasthan, India, November.

Clemment, P. 2010. The Term "Macroprudential": Origins and Evolution. Quarterly Review, Bank for International Settlement, Maret.

Committee on the Global Financial System. 2010. Macroprudential Instruments and Frameworks: A Stocktaking of Issues and Experiences. CGFS Papers, No.38. Bank for International Settlements, Mei.

Committee on the Global Financial System. 2012. Operationalising the Selection and Application of Macroprudential Instruments. CGFS Papers, No. 48. Bank for International Settlements, Desember.

Cui, Yuhu, dan Ansgar Belke. 2008. Monetary Policy Interdependence between the ECB and The Fed: VARX Model versus VEC Model.International Conference on Applied Economics, Mei.

Delgado, Fernando L., dan Mynor Meza. 2011. Developments in Financial Supervision and the use of Macroprudential Measures in Central America. IMF Working Paper, WP/11/299, Desember.

G20 Finance Ministers and Central Bank Governors. 2011. Macroprudential Policy Tools and Frameworks. Financial Stability Board, International Monetary Fund, dan Bank for international Settlements, Februari.

Galati, Gabriele dan Richhild Moessner. 2011. Macroprudential Policy - A Literature Review. Working Paper No. 337. Bank for International Settlements, Februari.

Gauthier, Celine, Alfred Lehar, dan Moez Souissi. 2012. Macroprudential Capital Requirements and Systemic Risk. Journal of Financial Intermediation, No. 21: 594-618.

Gersbach, Hans, dan Jean-Charles Rochet. 2012. Aggregate Investment Externalities and Macroprudential Regulation. Journal of Money, Credit, and Banking, Vol. 44, No. 2: 73109.

Hahm, Joon-Ho, Frederic S. Mishkin, Hyun Song Shin, dan Kwanho Shin. 2011. Macroprudential Policies in Open Emerging Economies. Asia Economic Policy Conference. Februari.

Horvath, Csilla, Peter S.H. Leeflang, Jaap E. Wieringa, Dick R. Wittink. 2005. Competitive Reaction and Feedback Effects Based on VARX Models of Pooled Store Data. International Journal of Research in Marketing 22: 415-426.

International Monetary Fund. 2011. Macroprudential Policy: An Organizing Framework. Prepared by the Monetary and Capital Markets Department. 
International Monetary Fund. 2013. Key Aspects of Macroprudential Policy. Juni.

Lim, C., F. Columba, A. Costa, P. Kongsamut, A. Otani, M. Saiyid, T. Wezel, dan X. Wu. 2011. Macroprudential Policy: What Instruments and How to Use Them? Lessons from Country Experiences. IMF Working Paper, WP/11/238, Oktober.

Lima, Diana, Paul Levine, dan Joseph Pearlman. 2012. Optimal Macro-Prudential and Monetary Policy. University of Surrey, Agustus.

Mendicino, Caterina. 2012. Collateral Requirements: Macroeconomic Fluctuations and Macroprudential Policy. Working Paper No. 11, Banco de Portugal, April.

Milne, Alistair. 2009. Macro-prudential Policy: Is It Really So New?. Draft Paper for Oxford Review of Economic Policy. Desember.

Peraturan Bank Indonesia No.12/10 /PBI/2010 Tentang Perubahan Ketiga atas Peraturan Bank Indonesia. Nomor 5/13/PBI/2003

Peraturan Bank Indonesia Nomor 15/7/ PBI /2013 Tentang Perubahan Kedua Atas

Peraturan Bank Indonesia Nomor 12/19/ PBI /2010 Tentang Giro Wajib Minimum Bank Umum Pada Bank Indonesia Dalam Rupiah Dan Valuta Asing.

Peraturan Bank Indonesia Nomor: 12/19/ PBI /2010 Tentang Giro Wajib Minimum Bank Umum Pada Bank Indonesia Dalam Rupiah Dan Valuta Asing

Peraturan Bank Indonesia Nomor: 5/13/PBI/2003 Tentang Posisi Devisa Neto Bank Umum

Peraturan Bank Indonesia. Nomor: 12/ 11 / PBI /2010 Tentang. Operasi Moneter

Progress Report to G20. 2011. Macroprudential Policy Tools and Frameworks. Financial Stability Board, International Monetary Fund, Bank for International Settlements, Oktober.

Quint, Dominic dan Pau Rabanal. 2011. Monetary and Macroprudential Policy in an Estimated DSGE Model of the Euro Area. $12^{\text {th }}$ Jacques Polak Annual Research Conference, November.

Schoenmaker, Dirk dan Peter Wierts. 2011. Macroprudential Policy: The Need for a Coherent Policy Framework. Duisenberg School Finance Policy Paper Series, No. 13, Juli.

Tovar, Camilo E., Mercedes Garcia-Escribano, and Mercedes Vera Martin. 2012. Credit Growth and the Effectiveness of Reserve Requirements and Other Macroprudential Instruments in Latin America. IMF Working Paper, WP/12/142, Juni. 
Utari, Diah dan Arimurti, Trinil. 2011. A Macro-Prudential Assessment For Indonesia. Bank Indonesia.

http://www.seacen.org/file/file/RP88/framework\%20chap3.pdf.

diunduh Desember 2013

Working Group G-30. 2010. Enhancing Financial Stability and Resilience: Macroprudential Policy, Tools, and Systems for the Future. Working Paper G-30 
Halaman ini sengaja dikosongkan 